\title{
Student and Faculty Perceptions of Live Synchronous Distance Education for Allied Health Students Following Program Expansion to a Rural Campus
}

\author{
Betsy J. Becker \\ University of Nebraska Medical Center, betsyj.becker@unmc.edu \\ Kelsey Rutt \\ University of Nebraska Medical Center, knrutt@hotmail.com \\ Allyson Huntley \\ University of Nebraska Medical Center, huntleyam12@gmail.com \\ Harlan Sayles \\ University of Nebraska Medical Center, hsayles@unmc.edu \\ Kim Michael \\ University of Nebraska Medical Center, kkmichael@unmc.edu \\ Follow this and additional works at: https://nsuworks.nova.edu/ijahsp \\ Part of the Curriculum and Instruction Commons, Educational Methods Commons, Higher Education \\ and Teaching Commons, Interprofessional Education Commons, Medical Specialties Commons, Online \\ and Distance Education Commons, Other Medical Sciences Commons, Physical Therapy Commons, and \\ the Scholarship of Teaching and Learning Commons
}

\section{Recommended Citation}

Becker BJ, Rutt K, Huntley A, Sayles H, Michael K. Student and Faculty Perceptions of Live Synchronous Distance Education for Allied Health Students Following Program Expansion to a Rural Campus. The Internet Journal of Allied Health Sciences and Practice. 2018 Jan 01;16(4), Article 9.

This Manuscript is brought to you for free and open access by the College of Health Care Sciences at NSUWorks. It has been accepted for inclusion in Internet Journal of Allied Health Sciences and Practice by an authorized editor of NSUWorks. For more information, please contact nsuworks@nova.edu. 


\title{
Student and Faculty Perceptions of Live Synchronous Distance Education for Allied Health Students Following Program Expansion to a Rural Campus
}

\begin{abstract}
Background \& Purpose: Distance education (DE) is a means to meet allied health workforce needs in rural locations where healthcare worker shortages are apparent. Five allied health programs were expanded to a rural campus teaching synchronously using distance education technology. The purpose of this convergent parallel mixed methods study was to explore perceptions of allied health students and faculty at two campus locations.

Methods: Quantitative and qualitative information were collected through a survey of students and faculty (physical therapy, physician assistant, and medical imaging [diagnostic medical sonography, radiography, magnetic resonance imaging] programs). Both campuses served as live and distance sites depending on instructor location and area of content expertise. For example, morning courses may be taught live from one campus, and afternoon classes taught live from the other campus. Only one program, physical therapy, offered labs by distance education. Response distributions were compared for questions by campus using Cochran-Armitage trend tests and analyzed de-identified qualitative comments using constant comparisons to establish themes.
\end{abstract}

Results: Student $(n=121)$ and faculty $(n=19)$ mostly agreed distance education technology was effective for teaching and learning. Significant differences were found in student opinions about receiving a similar educational experience between the two campuses. More students at the Main campus somewhat or strongly disagreed $(n=34,37 \%)$ it was similar compared to the Rural campus $(n=5,17 \%, p=0.024)$. There were no comments specifically related to the physical therapy lab experience. Open-ended comment themes included training, purposeful engagement of both campus locations, and setting clear expectations.

Conclusions: Although differences in learning experiences exist between the main and rural campus locations; the results indicated using distance education technology is an effective means to deliver the curriculum. Both students and faculty commented about the lack of experience with the educational technology before implementation. Synchronous, distance education offers the opportunity for program expansion and effective delivery of curriculum content. Using the results of this study can enhance future education in allied health professions using synchronous distance education technology.

\section{Author Bio(s)}

Betsy J. Becker, PT, DPT, CLT-LANA is an Assistant Professor and Associate Director of the Division of Physical Therapy Education in the College of Allied Health Professions at the University of Nebraska Medical Center in Omaha, NE.

Kelsey Rutt, BS, RT(R), RDMS is a former student in Diagnostic Medical Sonography in the Department of Medical Imaging and Therapeutic Sciences in the College of Allied Health Professions at the University of Nebraska Medical Center.

Allyson Huntley, BS, RT(R), RDMS, RVT is a former student in Diagnostic Medical Sonography in the Department of Medical Imaging and Therapeutic Sciences in the College of Allied Health Professions at the University of Nebraska Medical Center.

Harlan Sayles, MS is a Statistical Coordinator in the Department of Biostatistics in the College of Public Health at the University of Nebraska Medical Center.

Kim Michael, MA, RT(R), RDMS, RVT, FSDMS is the Associate Director of the Interprofessional Academy of 
Educators and Program Director, Associate Professor, and Anderson Distinguished Professor in Diagnostic Medical Sonography in the Department of Medical Imaging and Therapeutic Sciences in the College of Allied Health Professions at the University of Nebraska Medical Center.

\section{Acknowledgements}

The authors would like to thank Cherie Kimble, Administrative Associate II in the College of Allied Health Professions (CAHP), for her hard work in formatting the survey and Fran Higgins, MA, ADWR, with communications, web and media in the CAHP for her assistance with final manuscript editing. 


\title{
1IJAHSP \\ The Internet Joưnal of Allied Health Sciences and Practice \\ Dedicated to allied health professional practice and education \\ Vol. 16 No. 4 ISSN 1540-580X
}

\section{Student and Faculty Perceptions of Live Synchronous Distance Education for Allied Health Students Following Program Expansion to a Rural Campus: A Mixed Methods Study}

\author{
Betsy J. Becker, PT, DPT, CLT-LANA \\ Kelsey Rutt, BS, RT(R), RDMS \\ Allyson Huntley, BS, RT(R), RDMS, RVT \\ Harlan Sales, MS \\ Kim Michael, MS, RT(R). RDMS, RVT, FSDMS \\ University of Nebraska Medical Center
}

United States

\begin{abstract}
Background: Distance education (DE) is a means to meet allied health workforce needs in rural locations where healthcare worker shortages are apparent. Five allied health programs were expanded to a rural campus teaching synchronously using distance education technology. The purpose of this convergent parallel mixed methods study was to explore perceptions of allied health students and faculty at two campus locations. Methods: Quantitative and qualitative information were collected through a survey of students and faculty (physical therapy, physician assistant, and medical imaging [diagnostic medical sonography, radiography, magnetic resonance imaging] programs). Both campuses served as live and distance sites depending on instructor location and area of content expertise. For example, morning courses may be taught live from one campus, and afternoon classes taught live from the other campus. Only one program, physical therapy, offered labs by distance education. Response distributions were compared for questions by campus using Cochran-Armitage trend tests and analyzed de-identified qualitative comments using constant comparisons to establish themes. Results: Student $(n=121)$ and faculty $(n=19)$ mostly agreed distance education technology was effective for teaching and learning. Significant differences were found in student opinions about receiving a similar educational experience between the two campuses. More students at the Main campus somewhat or strongly disagreed $(n=34$, $37 \%)$ it was similar compared to the Rural campus ( $n=5,17 \%, p=0.024)$. There were no comments specifically related to the physical therapy lab experience. Open-ended comment themes included training, purposeful engagement of both campus locations, and setting clear expectations. Conclusions: Although differences in learning experiences exist between the main and rural campus locations; the results indicated using distance education technology is an effective means to deliver the curriculum. Both students and faculty commented about the lack of experience with the educational technology before implementation. Synchronous, distance education offers the opportunity for program expansion and effective delivery of curriculum content. Using the results of this study can enhance future education in allied health professions using synchronous distance education technology.
\end{abstract}

Key Words: distance education, synchronous, rural, allied health 


\section{INTRODUCTION AND BACKGROUND}

Technological advances in medical care, trends for preventive care, chronic disease, and an aging population all contribute to a growing need for trained healthcare professionals. Allied health professions comprise approximately $60 \%$ of the healthcare workforce and include approximately 80 to 100 healthcare occupations that are non-medicine and non-nursing. ${ }^{1}$ The use of distance learning or distance education is a means to meet the growing workforce need by educating more students and educating students in rural locations where the healthcare worker shortage may be more apparent. Distance education in the health professions allows optimal use of programmatic and community resources. Allied health programs delivered to two or more sites allows a content expert to share knowledge to all students in the program reducing the need to hire specialty faculty at each campus or limiting the faculty expertise to one group of students. Quality clinical sites and clinical preceptors are rate- limiting factors for program expansion in a community. Distance education technology helps reduce this issue by increasing the number of available clinical sites and preceptors at a location away from the primary campus. Possible benefits to the student include the opportunity to stay and learn in their community, reducing the cost of relocation and increasing the emotional and physical support from their family. Through distance education, healthcare education programs can offer an equitable education to students at all sites, increase the number of graduates, and help meet the need for trained professionals.

Synchronous distance education allows learners at a distance site to connect live to see, hear, and interact with the instructor and their classmates at another location. Many studies about student learning and faculty teaching synchronously via distance education show no significant difference in the course grades or student satisfaction between the face-to-face and distance students, but there are conflicting outcomes data in health professions education programs. ${ }^{2 \cdot 7}$ Student-student interaction, facultystudent interaction, and student-content interaction is needed for any successful educational environment and is key to the distance education environment.8,9 A study by Abdous and Yen comparing three modes of educational delivery, face-to-face, satellite broadcasting, and live video streaming results showed the level of self-perceived student-to-teacher interaction remained similar across delivery mode groups concerning teacher presence and availability, but the perceived level of equivalent interaction required additional faculty effort and attention. 5,8 The degree of self-perceived faculty-student interaction is a predictor of student satisfaction and learning outcomes, and a strong motive for faculty to create an interactive classroom environment no matter what the method of delivery. Classroom interactivity can be disrupted by technology issues. With synchronous distance education, this disruption affects learners not only at the distance site but at the originating site.,10 This study will fill a gap in the literature about faculty and student experiences in healthcare courses delivered synchronously via distance education, and results will be used to improve educational delivery in allied health courses.

In the fall of 2015, an academic medical center in the Midwest opened a new Health Sciences Education Complex on a sister campus. The sister ("Rural") campus is in a rural area, 2016 metro area population 55,935, approximately 200 miles away from the main ("Main") university campus in a larger metropolitan area, 2016 metro area population $~ 924,129.11$ The new Health Sciences Education Complex expanded five allied health programs (physical therapy, physician assistant, diagnostic medical sonography, radiography, and magnetic resonance imaging) to this rural part of the state. The goal of the expansion was to help address the shortage of allied health care professionals in this state by making the educational programs more accessible to students who live far from the Main urban campus. Classes were taught at each location synchronously using Vidyo (Hackensack, $\mathrm{NJ}$ ), a video conferencing platform. This technology allowed students to remain in their community and interact in real time with their classmates and faculty in both locations. With faculty at both campus locations, the origination of course delivery alternated between the campuses allowing both student populations to experience in-class and distance delivery modes. Both the Main and Rural sites served as the live and distance sites. For example, some morning courses were taught live from the Main site, and the afternoon classes were taught live from the Rural location. Faculty strived to create an interactive classroom to build community among the students at both sites, as well as with the instructor. For many students, this was the first time they learned in this type of environment or used this specific type of technology. We covered an introduction to this educational technology during the first week of program orientation. Faculty was trained on the use of the technology at scheduled in-services and through online tutorials.

By evaluating the results of this study, we will gain valuable insight to help improve the learning environment for allied health students and faculty who use distance education technology. Our results will be implemented to prepare current and future students for the distance education experience and train faculty for teaching in this setting. Our study is comprehensive because we consider student and faculty perspectives using quantitative data and qualitative responses.

The purpose of this mixed methods study was to explore perceptions of allied health students and faculty who used distance learning technology in five different allied health science curriculums and two campus locations. This study was a convergent parallel mixed methods design where qualitative and quantitative data were collected in parallel, analyzed separately, and then merged in the discussion. In this study, survey data was used to measure opinions about distance education technology for

( The Internet Journal of Allied Health Sciences and Practice, 2018 
synchronized learning and teaching among students and faculty at the Main campus and Rural campus locations. At the same time, qualitative data from open-ended survey questions explored the opinions of students and faculty related to distance education at each campus location. The reason for collecting both quantitative and qualitative data is to converge and compare results from the two forms of data to bring greater insight into the issue than would be obtained by either type of data separately. The research questions that guided our study were 1) What strategies are effective for preparing and delivering a distance education course? 2) What techniques do faculty utilize to make the distance experience positive? and 3) Are there differences in perceptions of experiences between the Rural and Main campus sites for students and faculty?

\section{METHODS}

Students enrolled in the Doctor of Physical Therapy (PT), Master of Physician Assistant (PA), and Bachelor of Science or PostBaccalaureate Professional Certificate in Medical Imaging and Therapeutic Sciences (e.g., diagnostic medical sonography, radiography and magnetic resonance imaging) at a Midwestern public academic health science university who had completed at least one semester via distance education were eligible for the study. They were recruited via e-mail and announcements made in class. Inclusion criteria for faculty participation included those with a faculty appointment in the College of Allied Health Professions and at least one semester of teaching experience via distance education in their respective allied health program curriculum.

Surveys allowed participants to express their perceptions, ideas and feelings toward our topic of interest using closed- and openended items. This data collection method was most appropriate for our study because we wanted a large number of participants from multiple allied health programs and to collect responses in a short timeframe from the end of the semester. Interviews were not appropriate for our study given the many participants we wanted to include, short amount of time to collect and analyze the information before results could be disseminated for meaningful impact to our allied health programs, and no funding for this project. $^{12}$

The student and faculty surveys were developed with input from two students and two faculty in the College of Allied Health with experience in distance education and in collaboration with a biostatistician with expertise in survey research. Of these survey developers, responses were collected from one of the faculty members (KM). We did not ask about the classroom or lab distance education experiences separately because we considered any use of distance education experiences part of the curriculum. The online survey was distributed using Survey Monkey (San Mateo, CA) with an anonymous link via email to students and faculty. No identifying information was attached to the survey link. We used Dillman's tailored survey methods to increase survey response and sent up to four emails to each participant including a pre-survey announcement, notification of the survey, and two reminders. ${ }^{13}$ In the survey questions, we defined the distance site as the location where the students were watching a class session using video conferencing educational technology and the live site was defined as the location where the in-person faculty was located. Our student survey was composed of closed-ended questions including demographic information (allied health program, campus location, age, and gender) and five questions about their distance education experience including impact, training on technology, connection with classmates and instructors, and overall effectiveness. The open-ended questions asked about perceptions of optimal learning environments, what information they needed about distance education, and tips for students and faculty for future courses. The faculty survey included closed-ended questions like the student survey, with small wording changes to indicate teaching versus learning via distance education. The demographic questions included were campus location and allied health programs. We asked faculty three open-ended questions that paralleled the student questions including effective strategies when teaching via distance education, information they could have used before teaching via distance, and techniques to make the experience optimal.

Response distributions were compared for each quantitative question by campus location (Main and Rural) using CochranArmitage trend tests, where a p-value less than 0.05 was considered a statistically significant difference in the response trends between campuses. Institutional Review Board approval was received for this study and consent to participate by students and faculty was indicated by submission of the survey.

Qualitative survey questions were analyzed after all data were de-identified and aggregated from the online survey tool. Two faculty used the constant comparisons method for analyzing qualitative comments from student and faculty surveys independently and then together. Additionally, two students assisted with the coding of the student comments. This strategy resulted in separate categories of data for the faculty and student respondents that were combined and collapsed into themes reaching a good fit for the meaning. ${ }^{14}$

\section{RESULTS \\ Quantitative}

(c) The Internet Journal of Allied Health Sciences and Practice, 2018 
There were 121 student responses with 92 from the Main campus and 29 from the Rural campus (response rate: 121/174 =70\%). The student study sample included 49 (38 Main, 11 Rural, 84\% response rate) from PT, 41 (34 Main, 7 Rural, 69\% response rate) $\mathrm{PA}$, and 31 (20 Main, 11 Rural, 59\% response rate) from Medical Imaging programs. Of the student respondents, 96 were female $(79 \%), 25$ male $(20 \%)$, and the majority were $18-23$ years of age $(n=75$ or $62 \%)$. Other reported age demographics included 24 to 28 years, $n=40(33 \%) ; 29$ to 33 years, $n=4(3 \%)$; and 34 or above, $n=2(2 \%)$. We received 19 faculty responses including four from the Rural and the remaining from the Main campus (response rate: $19 / 25=76 \%$ ). Faculty response distribution was PT-26\%, PA-37\% and Medical Imaging-37\%. The approximate percentage of time the Main campus was the live site for Imaging and PT was $80 \%$ and PA $90 \%$, and the remainder of the time, the Rural campus was the live site.

Over $70 \%$ ( $n=88$ ) of students strongly or somewhat agreed that distance education technology was an effective method to deliver course content and there were no significant differences between campus locations $p=0.138$ (Table 1). In contrast, faculty responses from the Rural campus resulted in no one strongly agreeing and only two (11\%) somewhat agreed while $10(67 \%)$ Main campus faculty strongly or somewhat agreed it was effective. There were no differences between campus locations for faculty responses.

TABLE 1. Student and Faculty Responses by Campus Location to the statement, Distance education technology is an effective method to deliver course content to a distance site.

\begin{tabular}{|c|c|c|c|c|c|c|}
\hline & \multicolumn{3}{|c|}{ STUDENT responses } & \multicolumn{3}{|c|}{ FACULTY responses } \\
\hline & \multicolumn{2}{|c|}{$\begin{array}{l}\text { Campus Location } \\
\qquad(p=0.138)\end{array}$} & \multirow[b]{2}{*}{$\begin{array}{l}\text { Total } \\
\mathrm{n}(\%)\end{array}$} & \multicolumn{2}{|c|}{$\begin{array}{l}\text { Campus Location } \\
\qquad(p=0.436)\end{array}$} & \multirow[b]{2}{*}{$\begin{array}{l}\text { Total } \\
\mathrm{n}(\%)\end{array}$} \\
\hline & $\begin{array}{l}\text { Rural } \\
\mathrm{n}(\%)\end{array}$ & $\begin{array}{l}\text { Main } \\
\mathrm{n}(\%)\end{array}$ & & $\begin{array}{l}\text { Rural } \\
\mathrm{n}(\%)\end{array}$ & $\begin{array}{l}\text { Main } \\
\mathrm{n}(\%)\end{array}$ & \\
\hline Strongly Agree & $9(31.03)$ & $24(26.09)$ & $33(27.27)$ & $0(0.00$ & $6(40.00)$ & $6(31.58)$ \\
\hline Somewhat Agree & $15(51.72)$ & $40(43.48)$ & $55(45.45)$ & $2(50.00)$ & $4(26.67)$ & $6(31.58)$ \\
\hline Neutral & $5(17.24)$ & $20(21.74)$ & $25(20.66)$ & $2(50.00)$ & $3(20.00)$ & $5(26.32)$ \\
\hline Somewhat Disagree & $0(0.00)$ & $7(7.61)$ & $7(5.79)$ & $0(0.00)$ & $2(13.33)$ & 2 (10.53) \\
\hline Strongly Disagree & $0(0.00)$ & $1(1.09)$ & $1(0.83)$ & $0(0.00)$ & $0(0.00)$ & $0(0.00)$ \\
\hline Total & 29 & 92 & 121 & 4 & 15 & 19 \\
\hline
\end{tabular}

There was a statistically significant difference between campus locations regarding student perceptions about receiving a similar educational experience when learning at the distance site. More students at the Main campus somewhat or strongly disagreed $(n=34,37 \%)$ compared to the Rural campus, $(n=5,17 \%, p=0.024)$ even though the majority from both campus locations strongly or somewhat agreed (Table 2). Similarly, we asked faculty about the similarity of the educational experience when teaching from the distance site. More Main campus faculty somewhat or strongly disagreed $(n=5,33 \%)$ compared to the Rural campus $(n=0$, $0 \%$ ), although this observed trend did not provide enough evidence to demonstrate a significant difference between campuses.

Table 2. Student and Faculty Responses by Campus Location to the statement, When I am learning (student) or teaching (faculty) at the distance site, it is a similar educational experience as if I was live.

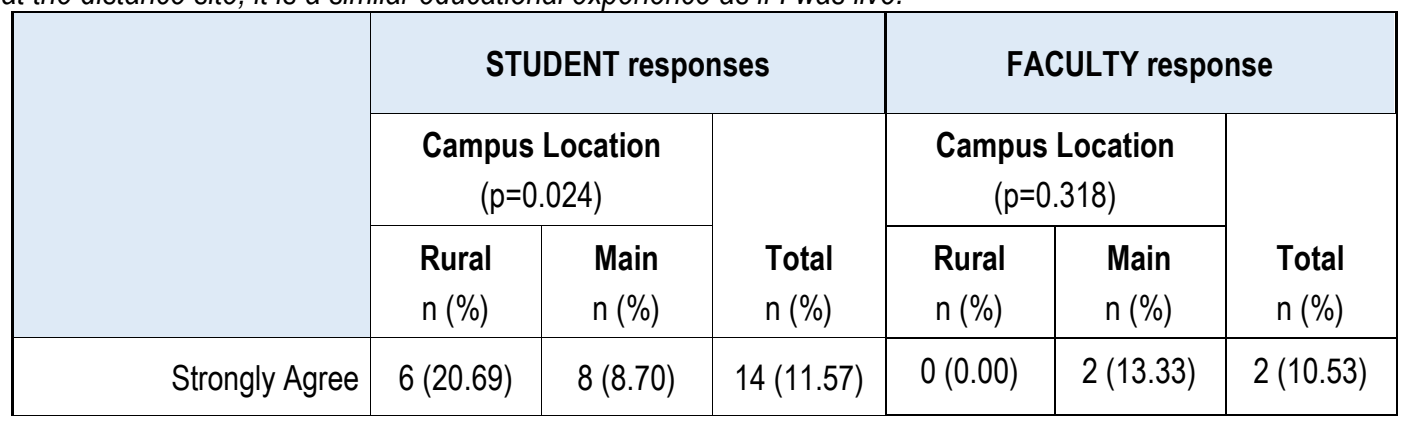

( The Internet Journal of Allied Health Sciences and Practice, 2018 


\begin{tabular}{|c|c|c|c|c|c|c|}
\hline & \multicolumn{3}{|c|}{ STUDENT responses } & \multicolumn{3}{|c|}{ FACULTY response } \\
\hline & \multicolumn{2}{|c|}{$\begin{array}{l}\text { Campus Location } \\
\qquad(p=0.024)\end{array}$} & \multirow[b]{2}{*}{$\begin{array}{l}\text { Total } \\
\mathrm{n}(\%)\end{array}$} & \multicolumn{2}{|c|}{$\begin{array}{l}\text { Campus Location } \\
\qquad(p=0.318)\end{array}$} & \multirow[b]{2}{*}{$\begin{array}{l}\text { Total } \\
\mathrm{n}(\%)\end{array}$} \\
\hline & $\begin{array}{l}\text { Rural } \\
\mathrm{n}(\%)\end{array}$ & $\begin{array}{l}\text { Main } \\
\mathrm{n}(\%)\end{array}$ & & $\begin{array}{l}\text { Rural } \\
\mathrm{n}(\%)\end{array}$ & $\begin{array}{l}\text { Main } \\
\mathrm{n}(\%)\end{array}$ & \\
\hline Somewhat Agree & $14(48.28)$ & $38(41.30)$ & $52(42.98)$ & $4(100.00)$ & $8(53.33)$ & $12(63.16)$ \\
\hline Neutral & $4(13.79)$ & $12(13.04)$ & $16(13.22)$ & $0(0.00)$ & $0(0.00)$ & $0(0.00)$ \\
\hline Somewhat Disagree & $4(13.79)$ & $25(27.17)$ & $29(23.97)$ & $0(0.00)$ & $3(20.00)$ & $3(15.79)$ \\
\hline Strongly Disagree & $1(3.45)$ & $9(9.78)$ & $10(8.26)$ & $0(0.00)$ & $2(13.33)$ & $2(10.53)$ \\
\hline Total & 29 & 92 & 121 & 4 & 15 & 19 \\
\hline
\end{tabular}

Most students at both campuses ( $n=25,86 \%$ Rural, $n=81,77 \%$ Main) reported strongly or somewhat agreeing that when they were in the live classroom or lab, using distance education technology minimally affected their educational experience (Table 3 ). There was no significant difference between students at each campus ( $p=.053)$. Most faculty strongly or somewhat agreed $(n=11,58 \%)$ using distance education technology minimally affected the educational experience, but there were also those who disagreed $(n=6$, $32 \%)$. No significant difference between campuses was noted for faculty responses.

Table 3. Student and Faculty Responses by Campus Location to the statement, When I am in a classroom or lab and the faculty or students are live in the same room with me, using educational technology minimally affects the educational experience.

\begin{tabular}{|r|c|c|c|c|c|c|}
\hline \multirow{2}{*}{} & \multicolumn{3}{|c|}{ STUDENT responses } & \multicolumn{3}{c|}{ FACULTY responses } \\
\cline { 2 - 4 } & \multicolumn{2}{|c|}{$\begin{array}{c}\text { Campus Location } \\
(\mathrm{p}=0.053)\end{array}$} & \multicolumn{2}{c|}{$\begin{array}{c}\text { Campus Location } \\
(\mathrm{p}=0.625)\end{array}$} & \\
\cline { 2 - 6 } & $\begin{array}{r}\text { Rural } \\
\mathrm{n}(\%)\end{array}$ & $\begin{array}{c}\text { Main } \\
\mathrm{n}(\%)\end{array}$ & $\begin{array}{c}\text { Total } \\
\mathrm{n}(\%)\end{array}$ & $\begin{array}{c}\text { Rural } \\
\mathrm{n}(\%)\end{array}$ & $\begin{array}{c}\text { Main } \\
\mathrm{n}(\%)\end{array}$ & $\begin{array}{c}\text { Total } \\
\mathrm{n}(\%)\end{array}$ \\
\hline Strongly Agree & $18(62.07)$ & $36(39.13)$ & $54(44.63)$ & $1(25.00)$ & $4(26.67)$ & $5(26.32)$ \\
\hline Somewhat Agree & $7(24.14)$ & $35(38.04)$ & $42(34.71)$ & $2(50.00)$ & 4() 26.67 & $6(31.58)$ \\
\hline Neutral & $3(10.34)$ & $12(13.04)$ & $15(12.40)$ & $0(0.00)$ & $2(13.33)$ & $2(10.53)$ \\
\hline Somewhat Disagree & $1(3.45)$ & $7(7.61)$ & $8(6.61)$ & $1(25.00)$ & $4(26.67)$ & $5(26.32)$ \\
\hline Strongly Disagree & $0(0.00)$ & $2(2.17)$ & $2(1.65)$ & $0(0.00)$ & $1(6.67)$ & $1(5.26)$ \\
\hline Total & 29 & 92 & 121 & 4 & 15 & 19 \\
\hline
\end{tabular}

Training how to use the technology for the distance education experience before starting a class was reported as beneficial for incoming students whether at the distance or host site as shown by $89 \%(n=26)$ at the Rural campus and $77 \%(n=71)$ at the Main campus strongly or somewhat agreed. Only six students reported either level of disagreement. There was a significant difference in the trend of the two response distributions $(p=.037)$. The Rural site reported more responses in the strongly agree category while those at the Main campus fell in the somewhat agree and neutral groups. Faculty also supported training with $84 \%(n=16)$ strongly agreeing it was beneficial, including all four Rural faculty.

\section{Qualitative}


There were 101 total student comments in response to the question, "What was helpful for taking a course using Vidyo distance education technology?" Of these, $40 \%(n=44)$ were tips for improved learning, $22 \%(n=24)$ were tips for faculty, $8 \%(n=9)$ were technology related, and the remainder $(n=24,22 \%)$ were comments unrelated to the question. Many of the tips for improved learning were about the importance of staying focused and the student's responsibility to find ways to make the classroom less distracting when at the distance site. This is illustrated with a comment from one student who said, "When you are at a distance site, try to interact as much as possible with the 'home' site of the lecture," and another student recommended to "pay full attention, take notes after lecture so you have no distractions during class."

Students also remarked on the importance of using the microphone without hesitation, so the class could run efficiently without constant reminders to do so and noting the importance of faculty being familiar with utilization of technology, so they do not get "flustered when it does not work." Students also reported faculty who know "how to do simple things helps greatly" such as using the chat feature between campus locations or adjusting the camera.

We also analyzed 23 faculty comments about strategies they found helpful when delivering a distance education course, and we discovered three themes. Over half $(57 \%, n=13)$ of the comments were related to student interactions, about a quarter $(26 \%$, $n=6)$ pertained to information technology for class preparations, and the remainder $(17 \%, n=4)$ were about backup plans when technology did not go as planned.

For faculty delivering a synchronous distance course, comfort level in the distance education classroom builds with experience, particularly experience related to familiarity with the equipment, which may vary slightly in each classroom, and become more confident in what instructional technique worked and what did not. One faculty member commented, "Sorry, I am still learning and don't have a strategy to offer," demonstrating the learning curve that instructors feel in this new setting. Another strategy recommended was getting "feedback before the end of the course evaluation" so adjustments can be made to improve the course environment before it is too late and the semester ends. Finally, one faculty advised traveling to a distance site to deliver course content so that all students experience learning in the origination site and at the distance site.

Students provided comments about strategies they wished they had known before taking a class using distance education technology. Of the 59 student comments, $59 \%$ ( $n=39)$ were related to more training, $27 \%(n=17)$ were tips for students to improve their learning, and $14 \%(n=8)$ were about how to solve technology issues. As mentioned previously, use of the microphone surfaced throughout the responses. One student reported the need to "use the mic every time we want to say even a one-word answer in a room of 120 people."

Comments about guest speakers and an idea to train students to help faculty with simple issues for efficient learning and usage of the distance technology illustrated training needs. Students also commented about unexpected and frequent technical problems regardless of campus and faculty not knowing the solutions.

Faculty perspectives mirrored the students' responses when asked what they would have liked to know before delivering a distance education course. Of the 17 comments, most related to the theme about information technology troubleshooting and education $(65 \%, n=11)$ but also about classroom and education tips such as video streaming, small group inter-campus discussions $(17 \%$, $n=3)$, or experience and practice $(17 \%, n=3)$. The learning environment theme was illustrated with comments about camera and microphone usage, setting early expectations for the students, and practicing with technology prior to live teaching. For example, one faculty reported wishing she had known earlier about the noise and distractions from students at the distance site that made it a difficult learning environment because she would have intervened. Another faculty remarked about "how much you need to practice to look and feel competent."

There were positive comments including improvements in flow with practice as the semester progressed. Faculty commented repeatedly about the inability to stream videos, and while there were reported "workarounds" for the issue, faculty were not happy with the disruption to the class flow. This issue was not mentioned by any students, which likely indicates that faculty handled these challenges well.

We received 100 comments from students about specific techniques their faculty used to make the distance learning experience optimal. Most comments related to involvement and inter-campus interaction ( $n=57,57 \%)$, followed by tips for faculty ( $n=16,16 \%)$, and technology issues $(n=27,27 \%)$. Students were complimentary in the efforts by faculty as shown by one who stated,

"faculty have gone above and beyond trying to be flexible with the distance learning. It would not be easy to be interrupted by technical difficulties when you're trying to deliver material to students, but they have worked hard to learn it."

( The Internet Journal of Allied Health Sciences and Practice, 2018 
Students also were appreciative of the engagement of faculty between the campuses using active learning techniques such as polling and asking, "specific questions to distance sites, giving us a chance to answer before the live (host) site."

Faculty responded with similar opinions about techniques used to make the classroom an optimal learning environment. Of the 20 comments, $35 \%(n=7)$ were about student interaction between campuses. One faculty member said it was beneficial to feel connected by "coming to class early to chat with students from both campuses," and several reported posing questions to students by alternating campus locations for the answers. Faculty reported two other themes including IT-related issues $(25 \%, n=5)$ and the importance of planning $(30 \%, n=6)$. One faculty described her very specific set-up for each class, indicating that organization and detailed planning likely made the experience optimal for student learning.

We received 65 total student comments about what they would have liked their instructors to know about teaching via distance education. Training for faculty was the most reported $(35 \%, n=23)$, followed by importance of student engagement $(n=18,28 \%)$, microphone/audio issues $(n=17,26 \%)$, and camera(s) $(n=7,11 \%)$. An example of a suggestion about student engagement was,

"Maybe get the two classes together at the beginning of the semester, so they are comfortable with each other- when being asked to speak into the microphone, I feel like I am talking to complete strangers at the other campus and I don't want to be wrong or look stupid."

Another idea was for faculty to be "extra vocal" to the distance site to keep them engaged. Again, microphone issues were reported and concerns about camera angles. Students said a reminder to faculty to "stay calm with technology issues" was important.

We asked faculty a variation of this question, to list tips that were helpful, and two themes emerged. The first and most common theme was successful teaching tips such as avoiding the use of a laser pointer since the distance site cannot view it, recommending that they instead use gestures, facial expressions, and voice inflections to be more engaging on screen, and complete a sound check and adjust the cameras to optimize audio and video for the distance students. The second theme was the importance of assistance with technology issues and making sure students at the distance site alerted faculty to issues immediately versus being concerned about interrupting class. Faculty quickly learned a "thumbs up" was not a substitute for a sound check because the check needed to be two-way.

\section{DISCUSSION}

The purpose of the study was exploring the perceptions of allied health students and faculty who use distance education technology in three different allied health science curriculums. There is now a better understanding of strategies students and faculty recommend for successful delivery of a distance education course. Student strategies focused primarily on the importance of interaction in the classroom. These strategies included selecting a seat which afforded a view of the instructor, putting away devices to reduce distraction, and asking and answering questions during class. Interaction, student-student or student-instructor, improves the distance classroom experience. $5,8,9$ Faculty reported working hard by practicing with technology and traveling to the distance site to increase familiarity with the other campus. Although practicing with technology is a strategy that is noted in the literature, traveling to the distance site is a novel approach that may not always be possible depending on the distance. 5,8,9 Students recognized these strategies by noting faculty going "above and beyond" to make the learning environment successful.

Specific techniques faculty utilized to make the distance experience positive for the students were identified. Faculty purposefully engaged students from both sites recognizing students by name versus a campus site, using audience response systems and alternating questions between campuses. All of these techniques helped to promote learner-to-teacher interaction which has been linked to student satisfaction in distance courses.5,8,9 Faculty were not pleased with the occasional technology issues interrupting class, but were innovative in workarounds and handled them professionally, as indicated by students.

There were comments from both students and faculty about the lack of familiarity with the distance educational technology and attribute these comments to several factors. First, due to competing demands on faculty time for scholarly activity, service, and administration, they may not have the allotted time to practice. Second, some faculty were more accustomed to using technology and found the challenge exciting; they picked up the nuances quickly while others had more difficulty. The skills with technology and its appropriate use are advocated in medical education and valuable for the changing educational delivery. ${ }^{15}$ Lastly, there were several technology challenges that occurred during class time that no amount of practice using it could have fixed. Technology issues have been shown to have a negative impact on the distance classroom for both the students and the instructor. ${ }^{2}$ Students expressed the need for training on how to use the microphones in each class and the importance of microphone use every time they speak. Students also reported that visiting professors were unfamiliar with the technology.

( The Internet Journal of Allied Health Sciences and Practice, 2018 
Students and faculty agree more training and faculty practice would be valuable. One outcome from this suggestion was the initiation of the Student Technology Assistance Team (STAT) in the PT Program. A group of 4 to 5 students from each campus volunteer to complete a 30-minute training with faculty and IT technicians. A program like this was already used in the Medical Imaging program with IT providing a brief introduction to the technology controls the first week of class along with a notebook on how to troubleshoot issues. Students have also become part of the solution in another way, as upper-class students provide training about proper use of microphones using humorous questions and answers during orientation. Also, faculty training sessions with IT personnel and peer-to-peer faculty training have occurred more frequently and we created a tip sheet for distance education (see Appendix).

There were differences in survey results between the Rural and Main campus sites and we attribute this to students at the Rural campus anticipating that this location would serve more frequently as the distance site while students at the Main campus expected most, if not all, of their education to be delivered on site. There were no differences in the qualitative comments between students at distance or host sites. Students reported similar concerns about the camera angle and microphone usage and similar suggestions about faculty getting more training and using students as impromptu-technology assistants. It was the distance site students who reported being easily distracted and provided solutions of purposefully trying to interact as much as possible with the host site and taking notes. It is interesting that despite these recommendations given by faculty at the beginning of the semester, it was not until students self-discovered these solutions they were deemed valuable. Faculty comments were similar across the campus locations with concerns about lost class time due to technology disruptions, unfamiliarity with teaching via distance, and using the technology for the first time. They learned what facilitated better teaching and learning along the way including calling on the distance site and host site specifically, occasionally traveling to the distance site to more fully-engage and build rapport with those students, and modeling professionalism when plans were disrupted.

Overall, students and faculty reported positive comments about their experiences at each campus location whether it was live or distance. Although students reported differences on the survey questions between live and distance sites, using distance education technology was considered an effective means to deliver the curriculum.

It should be noted that our study is not without limitations as we had fewer student respondents at the Rural site and did not measure the degree to which faculty-student engagement occurred with the students on either campus. Although both the Main and Rural campuses served as the distance site, the Rural campus was the distance site more frequently. This was in part due to the smaller number of students and faculty at the rural campus, as the programs controlled the expansion to maintain quality. In addition, because we did not complete interviews we could not ask follow-up questions to gain a deeper understanding of both the concerns and solutions provided in the written comments.

Future research on distance education could be completed through a multi-year study to account for the success of technology training and more routine use by students and faculty. A multi-institutional study of allied health student achievement, attrition, or satisfaction between campuses with distance education would be of value.

\section{CONCLUSION}

Distance education can be an effective method for delivering allied healthcare curriculum to students. Key strategies for successful deployment include both student and faculty training, purposeful engagement of each campus location, and setting clear expectations. Faculty need designated time for training on the distance educational technology to practice lecture and lab sessions before implementation. All students should have an introduction to the technology and a "low stakes" time to interact with the distance site prior to the official start of the first class. Additional training for natural student "techies" is also important.

Classroom engagement is the responsibility of both the faculty and the student. Faculty could arrive early and interact with both the on-site and distance students, use prepared questions and activities like online interactive quizzes to promote engagement, and provide ongoing reminders to students about using microphones. We recommend promoting the benefits of distance education technology for the opportunity to stay in the community, such as a rural location, at the start of the program. It should be acknowledged and emphasized that there will be technology issues, but with proper IT support and patience by the students and faculty, positive outcomes can result. Synchronous, distance education with video conferencing offers the opportunity for program expansion and effective delivery of curriculum content.

( The Internet Journal of Allied Health Sciences and Practice, 2018 


\section{References}

1. Association of Schools of Allied Health Professions. Available at: http://www.asahp.org/definition.htm. Updated 2017. Accessed August 17, 2018.

2. Libby LA, Boyd LD, Perry KR, Dominick C. Assessing student satisfaction with face-to-face synchronous distance education in a dental hygiene program. J Dent Educ. 2017;81(3):287-92. [PMID: 28250034]

3. Congdon HB, Nutter DA, Charneski L, Butko P. Impact of hybrid delivery of education on student academic performance and the student experience. Am J Pharm Educ. 2009;73(7):121. [PMID: 19960080]

4. Gadbury-Amyot CC, Purk JH, Williams BJ, Van Ness CJ. Using tablet technology and instructional videos to enhance preclinical dental laboratory learning. J Dent Educ. 2014;78(2):250-8. [PMID: 24489032]

5. Abdous M, Yen C. A predictive study of learner satisfaction and outcomes in face-to-face, satellite broadcast, and live videostreaming learning environments. Internet Higher Educ; Special Issue on Web 2.0. 2010;13(4):248-7.

6. Allen M, Bourhis J, Burrell N, Mabry E. Comparing student satisfaction with distance education to traditional classrooms in higher education: A meta-analysis. Am J Distance Educ. 2002;16(2):83-97.

7. Bagley JE, Randall K, Anderson MP. A comparison of sonography and radiography student scores in a cadaver anatomy class before and after the implementation of synchronous distance education. Ultrasound. 2015;23(1):59-66. [PMID: 27433237]

8. Abrami PC, Bernard RM, Bures EM, Borokhovski E, Tamim RM. Interaction in distance education and online learning: Using evidence and theory to improve practice. J Computing in Higher Educ. 2011;23(2):82-103.

9. Johnston J, Killion J, Oomen J. Student satisfaction in the virtual classroom. Internet Journal of Allied Health Professions. 2005;3(2).

10. Price JM, Whitlatch J, Jane Maier C, Burdi M, Peacock J. Improving online teaching by using established best classroom teaching practices. J Contin Educ Nurs. 2016;47(5):222-7. [PMID: 27124077]

11. Census B. Census website. Available at: https://www.census.gov/quickfacts/fact/table/Maincitynebraska/PST045216. Updated 2017.

12. Teddlie $C$, Tashakkori A. Data collection strategies for mixed methods research. In: Teddie $C$, Johnson RB, eds. Foundations of Mixed Methods Research: Integrating quantitative and qualitative approaches in the social and behavioral sciences.

Thousand Oaks, CA: Sage; 2009:217-248.

13. Dillman DA. Mail and Internet Surveys:The tailored designed method. John Wiley \& Sons; 2000.

14. Creswell JW. Research Design: Qualitative, Quantitative, and Mixed Methods approaches, 2e. Thousand Oaks, CA: Sage Publications; 2003.

15. Simpson D. Job roles of the 2025 medical educator. J Graduate Med Educ. 2018;10(3):243-6. [PMID: 29946376]

\section{Acknowledgments:}

The authors would like to thank Cherie Kimble, Administrative Associate II in the College of Allied Health Professions (CAHP), for her hard work in formatting the survey and Fran Higgins, MA, ADWR, with communications, web and media in the CAHP for her assistance with final manuscript editing. 
APPENDIX

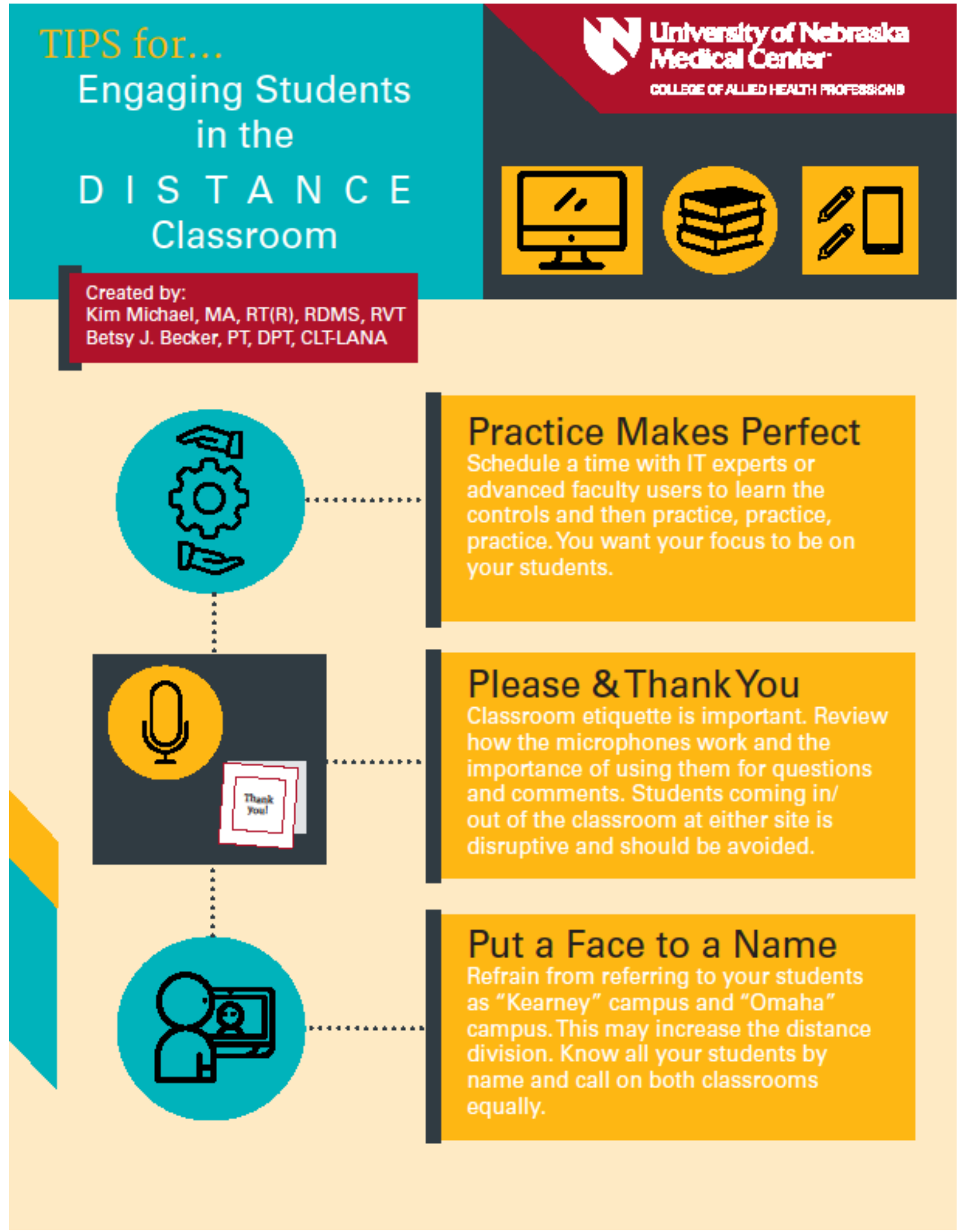




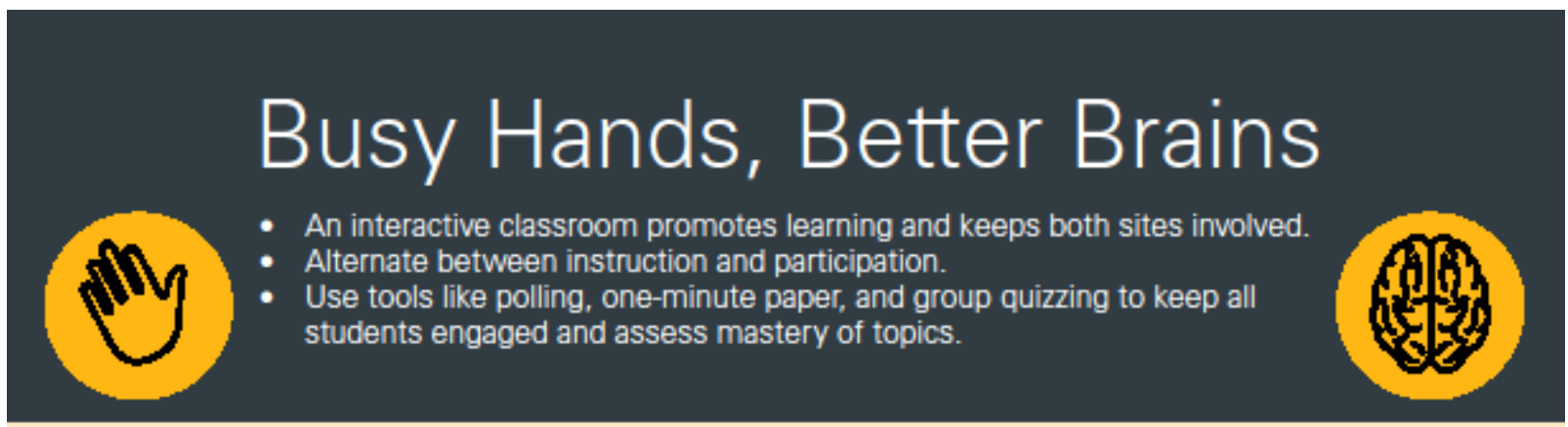

\section{Can you hear me now?}

Most classes have a "techie" that likes to assist faculty with technology issues. Identify these students early in the semester and let them know how much you appreciate their help. Have the students share cell phone numbers so when audio or video issues arise the student techies on both campuses can connect and alert faculty.

\section{Welcome to my 'Office'}

Instead of an email or phone call, consider using videoconferencing software for a face-to-face meeting with the student that is offcampus. This helps personalize your meeting and creates an environment that focuses on the student.

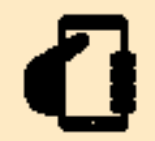

\section{Across the Miles

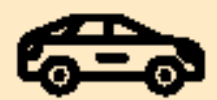

Assign projects or presentations that cut across the campuses and require students to interact outside the classroom setting in a smaller setting.

Although practice makes perfect, there may be times when you need an IT expert so keep their contact information handy.

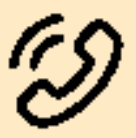

We would like to acknowledge contributions from: Mike Kozak, Tanya Custer, MS, RT(R)(T): Christina Gregg, BS, CNMT, RT(R)(N)(CT); Julie Morbach, MA, RDMS, RT(R); Kate Wampler, BS, RT(R), RDMS, RVT; Tammy L. Webster, MPA, RT(R)(M), and Fran Higgins, MA, ADWR.

Icons by Flaticon.com.

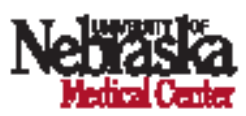

